Article

\title{
Monitoring Wheat Fusarium Head Blight Using Unmanned Aerial Vehicle Hyperspectral Imagery
}

\author{
Linyi Liu ${ }^{1,2}$, Yingying Dong ${ }^{1,2, *}$, Wenjiang Huang ${ }^{1,2}$, Xiaoping Du ${ }^{1,2}$ and Huiqin Ma ${ }^{1,2}$ \\ 1 Key Laboratory of Digital Earth Science, Aerospace Information Research Institute, \\ Chinese Academy of Sciences, Beijing 100094, China; liuly01@aircas.ac.cn (L.L.); \\ huangwj@aircas.ac.cn (W.H.); duxp@aircas.ac.cn (X.D.); mahq@aircas.ac.cn (H.M.) \\ 2 State Key Laboratory of Remote Sensing Science, Aerospace Information Research Institute, \\ Chinese Academy of Sciences, Beijing 100094, China \\ * Correspondence: dongyy@aircas.ac.cn; Tel.: +86-10-82178178
}

Received: 30 September 2020; Accepted: 17 November 2020; Published: 20 November 2020

check for updates

\begin{abstract}
The monitoring of winter wheat Fusarium head blight via rapid and non-destructive measures is important for agricultural production and disease control. Images of unmanned aerial vehicles (UAVs) are particularly suitable for the monitoring of wheat diseases because they feature high spatial resolution and flexible acquisition time. This study evaluated the potential to monitor Fusarium head blight via UAV hyperspectral imagery. The field site investigated by this study is located in Lujiang County, Anhui Province, China. The hyperspectral UAV images were acquired on 3 and 8 May 2019, when wheat was at the grain filling stage. Several features, including original spectral bands, vegetation indexes, and texture features, were extracted from these hyperspectral images. Based on these extracted features, univariate Fusarium monitoring models were developed, and backward feature selection was applied to filter these features. The backpropagation (BP) neural network was improved by integrating a simulated annealing algorithm in the experiment. A multivariate Fusarium head blight monitoring model was developed using the improved BP neural network. The results showed that bands in the red region provide important information for discriminating between wheat canopies that are either slightly or severely Fusarium-head-blight-infected. The modified chlorophyll absorption reflectance index performed best among all features, with an area under the curve and standard deviation of 1.0 and 0.0 , respectively. Five commonly used methods were compared with this improved BP neural network. The results showed that the developed Fusarium head blight monitoring model achieved the highest overall accuracy of $98 \%$. In addition, the difference between the producer accuracy and user accuracy of the improved BP neural network was smallest among all models, indicating that this model achieved better stability. These results demonstrate that hyperspectral images of UAVs can be used to monitor Fusarium head blight in winter wheat.
\end{abstract}

Keywords: remote sensing; wheat disease; classification; feature selection; BP neural network; disease monitoring

\section{Introduction}

As the dominant staple in most regions of North Africa as well as West and Central Asia, wheat (Triticum aestivum L.) is consumed by 2.5 billion people in 89 countries, and, annually, a total of 215 million hectares are used to grow wheat [1]. Wheat Fusarium head blight (FHB), or wheat scab, is an intrinsic infection by Fusarium graminearum (Gibberella zeae) [2]. The normal physiological function of FHB-infected wheat is destroyed, and both its internal physiological structure and external morphology change [3]. In addition, the disease produces a number of mycotoxins, of which deoxynivalenol (DON) 
is the most toxic. DON is toxic to both humans and animals, and is life threatening in severe cases [4]. The traditional method of FHB monitoring in the field uses visual inspection, which is time-consuming and inefficient, especially when large areas are monitored [5]. Moreover, the traditional method cannot provide precise distribution data of FHB within a particular wheat field, which often leads to the excessive use of pesticides [6].

With the development of Earth observation systems, research increasingly attempts to apply remote sensing technology for crop disease monitoring to increase the monitoring accuracy [7]. The theoretical basis of these studies is that the transpiration rate, chlorosis, leaf color, and morphology of crops will change in response to FHB infection. This ultimately leads to changes in the spectral reflectance characteristics of crops [1]. Many researchers have tried to monitor wheat FHB via remote sensing technology. Jin et al. (2018) applied a variety of deep neural network algorithms to hyperspectral images to identify FHB-infected areas. They found that a model based on a hybrid-structure deep neural network achieved the best performance for identifying FHB-infected areas [8]. Zhang et al. (2019) proposed the Fusarium classification index (FCI) for the detection of wheat FHB using hyperspectral microscopy images. The FCI was compared with six commonly used vegetation indexes to identify FHB-infected areas. The experimental results showed that the FCI achieved a better performance than other vegetation indexes [9]. Zhang et al. (2020) also monitored FHB using hyperspectral images. A deep convolutional neural network (DCNN) was established and achieved high monitoring accuracy with an $\mathrm{R}^{2}$ of 0.97 and a root mean square error (RMSE) of 3.78 [10].

As an effective method to generate high-frequency remote sensing information on crop conditions, unmanned aerial vehicles (UAVs) are widely used in agriculture. UAV data are used to estimate the leaf carotenoid content, biomass, nitrogen contents, and chlorophyll densities [11-14]. For two reasons, UAV imagery is particularly applicable to monitoring wheat FHB. First, the symptoms of wheat FHB, such as wrinkled, shrunken, and bleached organic tissue, commonly occur in the spikelets at the top of the wheat plant [15]. The spatial resolution of UAV images can reach $2-5 \mathrm{~cm}$ or less, and it is sufficiently high that the infected parts of wheat can be identified directly [16]. Second, the FHB epidemics in China are severe and frequent in areas with cloudy rain and fog, such as the middle and lower regions of the Yangtze River [17]. The fields in the optical satellite images of these areas are often covered by clouds, which reduces the usability of these images. The UAV platform has a flexible mission planning, and it could acquire images in better weather conditions [18].

UAV images can be divided into multispectral images and hyperspectral images according to the applied band settings. Multispectral images are produced by measuring the reflected energy in multiple specific sections of the electromagnetic spectrum through specific sensors [19]. Multispectral images have been applied for various remote sensing applications, such as vegetation monitoring, tree height estimations, and nitrogen status assessments [13,20,21]. With the further development of sensors and imaging technology, hyperspectral images have become increasingly available. Hyperspectral sensors can simultaneously measure the reflected energy of the target area with tens to hundreds of continuous and subdivided spectral bands in the ultraviolet, visible, near-infrared, and mid-infrared regions of the electromagnetic spectrum [19]. Thus, hyperspectral images are more sensitive to subtle changes in reflected energy. Until now, hyperspectral images from UAVs have been utilized for many assessments, such as crop yield prediction, loss assessment, vegetation classification, and soil salinity assessment [11,22-25]. In addition, many researchers used hyperspectral images from UAVs to detect crop pests and diseases, such as powdery mildew, locusts, anthracnose, and yellow rust [23,26-28]. However, wheat FHB has not been monitored using UAV hyperspectral imagery.

For this study, the hyperspectral images of UAV were applied to monitor wheat FHB in a wheat field. We hypothesized that FHB could cause changes in transpiration rate, chlorosis, leaf color, and morphology in infected wheat plants, which, in turn, affect spectral and textural characteristics of wheat in the hyperspectral images. Taking this into account, we proposed an approach that combined original spectral bands, vegetation indexes, and texture features to monitor the severity of wheat FHB. The main objectives of this paper are: (i) to extract some features that can indicate the spectral and 
textural characteristics of wheat, and select the features that are sensitive to wheat FHB; (ii) to develop a multivariate FHB monitoring model based on these sensitive features; and (iii) to apply a multivariate FHB monitoring model to map wheat FHB infection in the study area.

\section{Materials and Methods}

\subsection{Study Area and Dataset}

The experimental field investigated in this study is located in Lujiang County, Anhui Province, China. Its coordinates are $117^{\circ} 13^{\prime} 12^{\prime \prime} \mathrm{E}$ and $31^{\circ} 29^{\prime} 0^{\prime \prime} \mathrm{N}$. Winter wheat is the main crop produced in Lujiang County, and the main variety is Yangmai 25, which is susceptible to wheat FHB. This location has a north subtropical humid monsoon climate, with an average annual temperature of $15.8{ }^{\circ} \mathrm{C}$; the highest temperature is in July and the lowest temperature is in January. The average annual precipitation is $1188 \mathrm{~mm}$ and the rainy season lasts from June to July every year [29]. In this region, the soil belongs to alfisols and FHB is a major wheat disease [30]. Figure 1 shows the location of the field site.

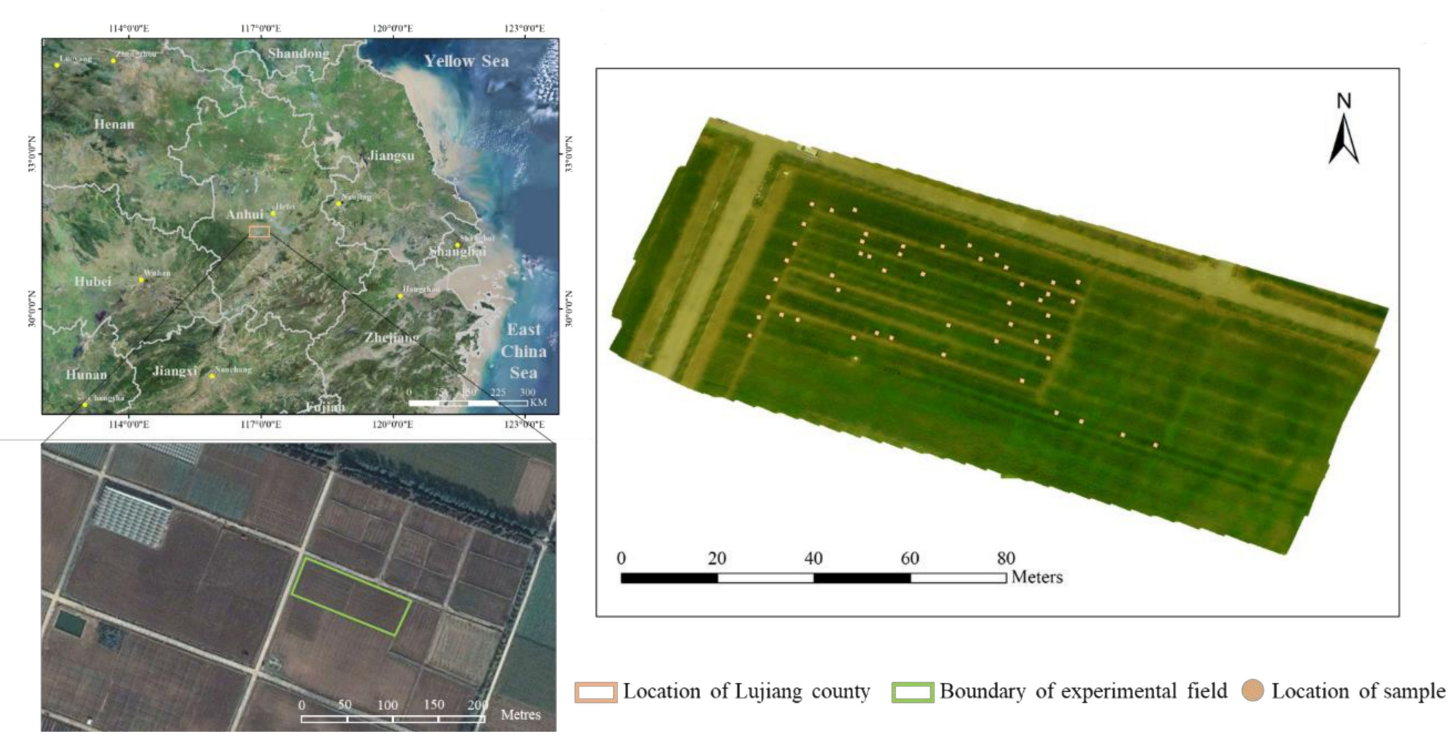

Figure 1. Location and sampling sites of the experimental field. The orange rectangle indicates the specific location of Lujiang County in Anhui, China, the green rectangle marks the boundary of the experimental field, and the orange dots indicate locations sampled for wheat fusarium head blight (the image on the upper left is a Gauthier satellite image, the image at the bottom left is a Google Earth satellite image, and the image on the right is the unmanned aerial vehicle (UAV) hyperspectral image acquired on 3 May 2019).

Hyperspectral UAV images were acquired on 3 and 8 May 2019, when the wheat was at the grain filling stage. The UAV used in the experiment was an M600 Pro aircraft of Daijang Innovations (DJI), and a Cubert S185 FireflEYE SE hyperspectral imaging camera was used. The spectral range of the S185 was from 450 to $950 \mathrm{~nm}$, and the average raw sampling width was $4 \mathrm{~nm}$. The radiance calibration of the hyperspectral imaging camera was carried out before capturing hyperspectral images. The camera exposure time was automatically matched to the environmental condition. The height above ground of the UAV was $60 \mathrm{~m}$, the flight speed was $3 \mathrm{~m} / \mathrm{s}$, camera triggering frequency was $0.8 \mathrm{~s}$, forward overlap was $80 \%$, and side overlap was $65 \%$. The spatial resolution of hyperspectral images was $4 \mathrm{~cm}$, and the raw number of bands in the imagery was 125. The area of the experimental field was $5000 \mathrm{~m}^{2}$, and uniform wheat cultivars, cultivation procedures, and management practices were applied to this field. All wheat plants in this field were infected with FHB because no pesticide was used at the early stage. Fifty plots, each with an area of $1 \mathrm{~m}^{2}$, were selected in the experimental field. To accurately locate 
the plots in hyperspectral images, a flag was placed next to each plot. The severity of the FHB of the plot was calculated according to the rules for monitoring and forecasting wheat head blight suggested by the National Plant Protection Department of China (Chinese Standard: GB/T 15796-2011) [31,32]. When inspecting the disease severity, 50 individual plants were randomly selected in every plot, and the symptoms of wheat FHB were identified by visual inspection. Then, the number of plants with infected spikelets was recorded, the ratio of infected plants in each plot was calculated, and all plots were classified into five classes according to the calculated ratio of infected plants: $0.1-10 \%$ (class 1), 10-20\% (class 2), 20-30\% (class 3), 30-40\% (class 4), and 40-100\% (class 5). In practice, wheat fields with more than $30 \%$ infected wheat ears would be destroyed because of the excessive harmful substances produced. Consequently, plots were quantitatively classified into two classes for subsequent analysis: Plots with a ratio of infected wheat ears to healthy wheat ears below 30\% were labeled as slightly diseased, and plots with a ratio exceeding 30\% were labeled as severely diseased. Figure 2 shows slightly diseased and severely diseased wheat canopies in red-green-blue (RGB) imagery captured by the UAV.
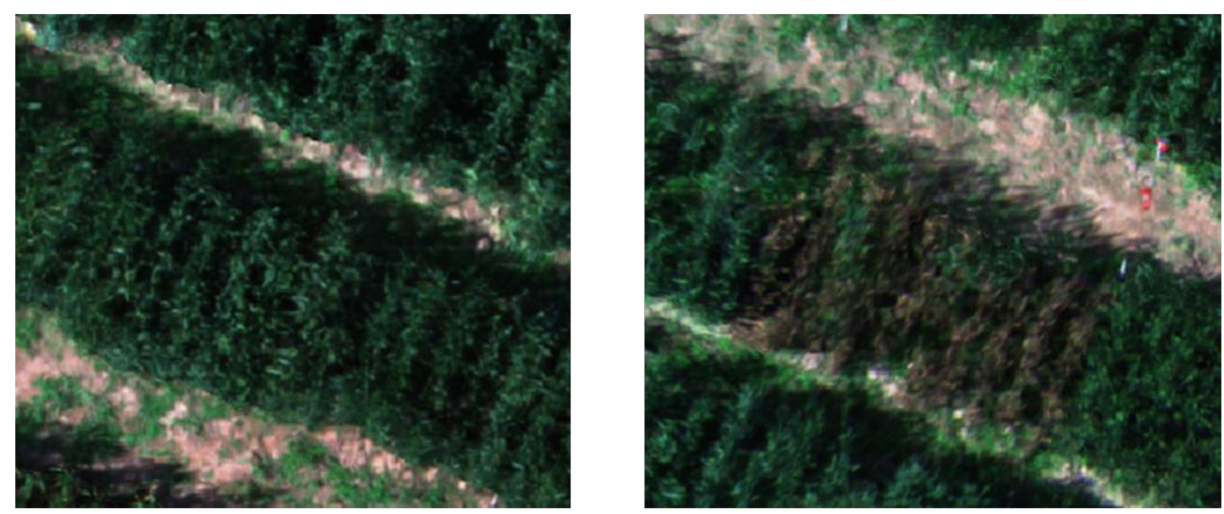

Figure 2. Slightly diseased (left) and severely diseased (right) wheat canopies in red-green-blue (RGB) imagery captured by the UAV.

\subsection{Data Preprocessing}

When acquiring UAV hyperspectral images, the drone was equipped with a position and orientation system to record the real-time position and attitude of the sensors. After the mission was completed, the images obtained from the UAV imaging spectrometer were a high-spatial-resolution panchromatic image (JPG format) and a low-spatial-resolution hyperspectral cube image (CUE format). Then, the fusion and stitching operations were carried out in CubertPolot and Photoscan, respectively. During the acquisition of hyperspectral images, noise would be added to the radiated energy output of the sensor due to the systematic errors in the sensor, and this resulted in a discrepancy between the radiation values of hyperspectral images and the true radiation values. Thus, a radiometric calibration was carried out using the following equation:

$$
\mathrm{L}=\mathrm{M} * \mathrm{DN}+\mathrm{A},
$$

where $\mathrm{L}$ is the radiation value, $\mathrm{M}$ is the gain, $\mathrm{A}$ is the bias, and $\mathrm{DN}$ is the pixel value. After that, atmospheric correction was used to remove the effects of the atmosphere on the reflectance values of hyperspectral images. Figure 3 shows the main steps of the methodological framework developed in this research. These steps are described below. 


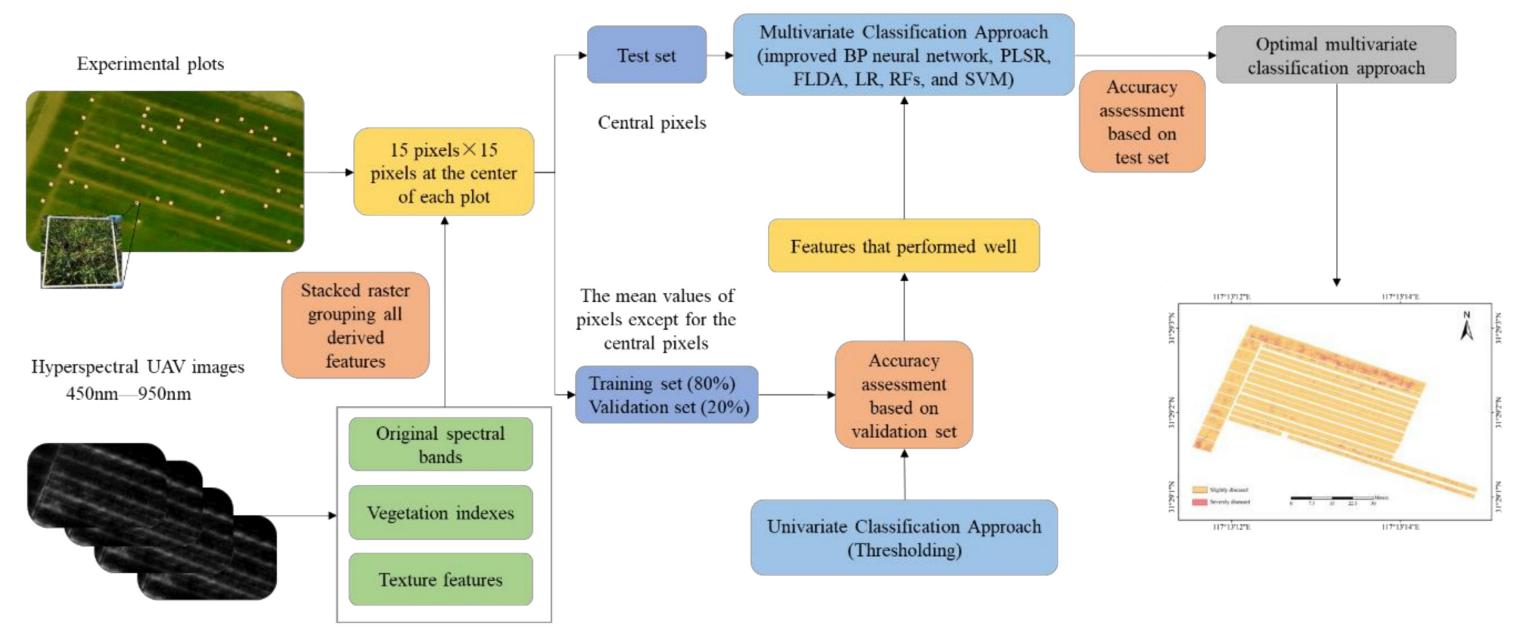

Figure 3. Methodological framework with the main steps.

When inspecting the quality of hyperspectral images, the first nine bands and the last 15 bands of each image were excluded because they were found to have been affected by noise during the post-process. Then, a number of features, including original spectral bands, vegetation indexes, and texture features, were extracted from these hyperspectral images.

After removal of all noise-affected bands, 101 bands remained in each hyperspectral image. Since the spectral sampling interval of hyperspectral images was small, two adjacent bands are highly correlated. In this study, an original spectral band was selected as a feature in every five adjacent bands to decrease the correlation between features, and the selection was carried out in a regular, consistent way, leading to a $20 \mathrm{~nm}$ sampling interval.

The vegetation indexes used in this study are commonly used in the monitoring of crop pests and diseases. Table 1 presents detailed descriptions of these vegetation indexes.

Table 1. Vegetation indexes used in this study.

\begin{tabular}{|c|c|c|c|}
\hline Title & Definition & Description or Formula & Reference \\
\hline PRI & Photochemical reflectance index & $\left(R_{570}-R_{531}\right) /\left(R_{570}+R_{531}\right)$ & [28] \\
\hline PhRI & Physiological reflectance index & $\left(R_{550}-R_{531}\right) /\left(R_{550}+R_{531}\right)$ & [33] \\
\hline NRI & Nitrogen reflectance index & $\left(\mathrm{R}_{570}-\mathrm{R}_{670}\right) /\left(\mathrm{R}_{570}+\mathrm{R}_{670}\right)$ & [34] \\
\hline NDVI & Normalized difference vegetation index & $\left(\mathrm{R}_{830}-\mathrm{R}_{675}\right) /\left(\mathrm{R}_{830}+\mathrm{R}_{675}\right)$ & [35] \\
\hline MSR & Modified simple ratio & $\left(\mathrm{R}_{800} / \mathrm{R}_{670}-1\right) / \mathrm{sqrt}\left(\mathrm{R}_{800} / \mathrm{R}_{670}+1\right)$ & [36] \\
\hline MCARI & Modified chlorophyll absorption reflectance index & $\begin{array}{c}\left(\left(\mathrm{R}_{701}-\mathrm{R}_{671}\right)-0.2\left(\left(\mathrm{R}_{701}-\right.\right.\right. \\
\left.\left.\mathrm{R}_{549}\right)\right) /\left(\mathrm{R}_{701} / \mathrm{R}_{671}\right)\end{array}$ & [37] \\
\hline GI & Greenness index & $\mathrm{R}_{554} / \mathrm{R}_{677}$ & [38] \\
\hline TVI & Triangular vegetation index & $0.5\left(120\left(R_{750}-R_{550}\right)-200\left(R_{670}-R_{550}\right)\right)$ & [39] \\
\hline TCARI & $\begin{array}{l}\text { Transformed chlorophyll absorption in } \\
\text { reflectance index }\end{array}$ & $\begin{array}{c}3\left(\left(\mathrm{R}_{700}-\mathrm{R}_{675}\right)-0.2\left(\mathrm{R}_{700}-\right.\right. \\
\left.\left.\mathrm{R}_{500}\right) /\left(\mathrm{R}_{700} / \mathrm{R}_{670}\right)\right)\end{array}$ & [40] \\
\hline RVSI & Ratio vegetation structure index & $\left(\left(R_{712}+R_{752}\right) / 2\right)-R_{732}$ & [41] \\
\hline PSRI & Plant senescence reflectance index & $\left(\mathrm{R}_{680}-\mathrm{R}_{500}\right) / \mathrm{R}_{750}$ & [42] \\
\hline
\end{tabular}

Several texture features were also extracted from these hyperspectral images. The texture of an image is a feature that reflects the homogeneity of the image. When the wheat canopy is infected by FHB, the ears of wheat will show brown spots, which gradually expand to the whole spikelet and cause the spikelet to shrivel [43]. Wheat canopies with different FHB-infection severities will have different texture features. The local binary pattern (LBP) was used to describe texture features in this 
study. The LBP is a commonly used local binary descriptor to describe the texture characteristics of an image [44]. The mathematical expression of the LBP is presented in the following:

$$
\begin{gathered}
\operatorname{LBP}_{(\mathrm{P}, \mathrm{R})}=\sum_{\mathrm{I}=0}^{\mathrm{P}-1} \mathrm{~S}\left(\mathrm{x}_{\mathrm{i}}-\mathrm{x}_{\mathrm{c}}\right) * 2^{\mathrm{i}},(\mathrm{i}=0,1, \ldots, \mathrm{P}-1) \\
\mathrm{s}(\mathrm{u})=\left\{\begin{array}{l}
1, \mathrm{u} \geq 0 \\
0, \mathrm{u}<0
\end{array}\right.
\end{gathered}
$$

where $\mathrm{P}$ represents the number of neighbors, $\mathrm{R}$ represents the radius, $\mathrm{i}$ represents one of the neighbors, $x_{i}$ represents the pixel value of $i$, and $x_{c}$ represents the pixel value of the central pixel. The proposed work used three combinations of $\mathrm{P}$ and $\mathrm{R}: \mathrm{P}=8$ and $\mathrm{R}=1\left(\operatorname{LBP}_{(8,1)}\right), \mathrm{P}=8$ and $\mathrm{R}=2\left(\operatorname{LBP}_{(8,2)}\right)$, and $\mathrm{P}=16$ and $\mathrm{R}=2\left(\operatorname{LBP}_{(16,2)}\right)$. Figure 4 shows the relationship between a pixel and its neighbors for three combinations of $\mathrm{P}$ and $\mathrm{R}$.

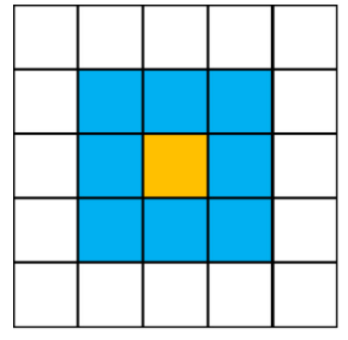

$\operatorname{LBP}_{(8,1)}$

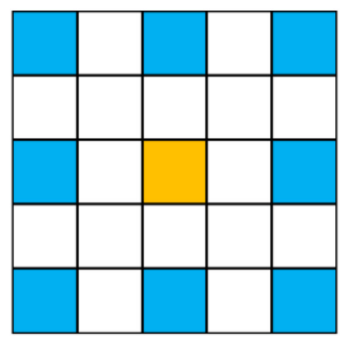

$\operatorname{LBP}_{(8,2)}$

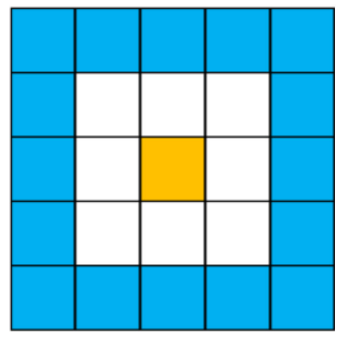

$\operatorname{LBP}_{(16,2)}$ Central pixel

Figure 4. General overview of the three types of local binary patterns (LBPs) used in this study.

When original spectral bands, vegetation indexes, and texture features were collected, the pixels located in experimental plots were extracted. Firstly, a support vector machine (SVM) was used to classify the pixels in the hyperspectral images into five categories: 1, bare soil; 2, road; 3 , wheat canopy; 4 , other plants; 5 , other non-plants. The pixel-based classification approach was applied because the pixels in the wheat canopy were well-defined and well-separated, and mixed pixels in the wheat canopy were abandoned in the end. The user accuracies and producer accuracies of all classes were higher than $80 \%$, and the overall accuracy was $87.14 \%$. In this experimental field, wheat is rarely mixed with other vegetation, and weeds are mainly distributed in trails between wheat fields. Thus, the errors between the "wheat canopy" and the "other plants" classes are small. Since the pixel-based classification result contained noise, majority/minority analysis was used in the post-processing of the classification to eliminate noise [45]. After identifying the pixels that belong to the wheat canopy, the wheat canopies close to a flag identifying the experimental plot were selected, and the pixels located in experimental plots were extracted. Considering the spatial resolution of hyperspectral images of $4 \mathrm{~cm}$ and the size of each plot of $60 \mathrm{~cm} \times 60 \mathrm{~cm}$, the pixels in the range of 15 pixels $\times 15$ pixels at the center of the selected wheat canopies were considered as being located in experimental plots. For each plot, the pixels located in the plot were chosen (except for the central pixel), and the values of these pixels were averaged. Eighty percent of these mean values and corresponding disease severities were used as the training set and $20 \%$ were used as the validation set to train and evaluate the FHB monitoring model. These mean values and corresponding disease severities were sorted randomly. The classification was repeated 100 times, and the average accuracy of the FHB monitoring model was calculated. Moreover, the values of central pixels in experimental plots and the corresponding disease severities were used as the test set. 


\subsection{Fusarium Head Blight Detection Using a Univariate Classification Approach}

Firstly, a univariate classification approach was used to develop the FHB monitoring model. The receiver operating characteristic (ROC) curve, which is widely used in remote sensing applications, was applied to evaluate the performance of the model to discriminate two types of plots. The construction of an ROC curve, as required for the identification of slightly diseased wheat and severely diseased wheat at the pixel level, was considered a binary classification problem, which results from the thresholding of a variable (original spectral bands, vegetation indexes, and texture features). For each pixel, the possible classification result is listed in Table 2.

Table 2. Possible classification result of a pixel.

\begin{tabular}{lccc}
\hline & \multicolumn{2}{c}{ Reference } \\
\hline \multirow{3}{*}{ Classification Result } & Slightly Diseased & Severely Diseased \\
\cline { 2 - 3 } & Slightly diseased & $\begin{array}{c}\text { True positive } \\
\text { (Slightly diseased pixel classified } \\
\text { as slightly diseased) }\end{array}$ & $\begin{array}{c}\text { False positive } \\
\text { (Severely diseased pixel classified } \\
\text { as slightly diseased) }\end{array}$ \\
\hline Severely diseased & $\begin{array}{c}\text { False negative } \\
\text { (Slightly diseased pixel classified } \\
\text { as severely diseased) }\end{array}$ & $\begin{array}{c}\text { True negative } \\
\text { (Severely diseased pixel classified } \\
\text { as severely diseased) }\end{array}$ \\
\hline
\end{tabular}

Two indicators of classification performance, sensitivity and specificity, were calculated using the following equations:

$$
\begin{aligned}
& \text { Sensitivity }=\text { TruePositive/(TruePositive }+ \text { FalseNegative }) \\
& \text { Specificity }=\text { TrueNegative/(TrueNegative }+ \text { FalsePositive) } .
\end{aligned}
$$

The ROC curve was drawn with sensitivity as the ordinate and 1-specificity as abscissa [46]. When evaluating the performance of a univariate FHB monitoring model, the values of the variable were given based on an initial value and a step. The corresponding values of specificity and sensitivity were calculated, and the ROC curve was obtained. Theoretically, the optimal value of the variable can be located in the ROC curve where the sum of sensitivity and specificity is at its maximum. In addition, the area under the ROC curve (AUC) was used to evaluate the overall classification performance of the univariate model. The values of AUC range from 0.0 to 1.0, and the higher the value, the better the classification performance of the univariate model; Figure 5 shows the general overview of the ROC curve and AUC.

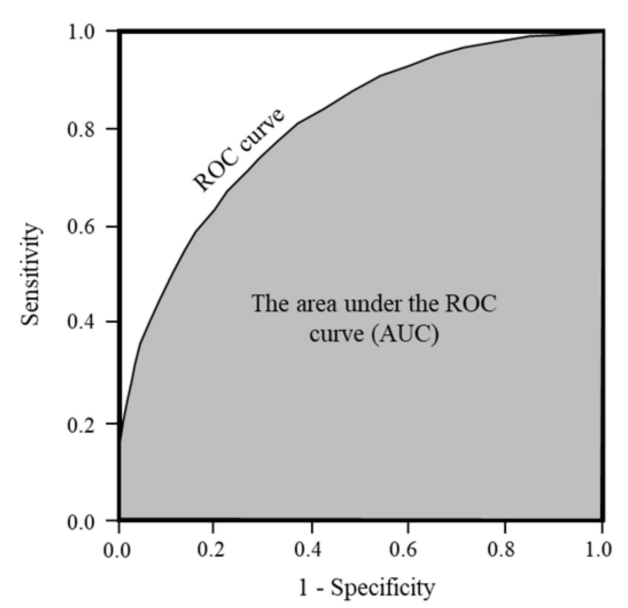

Figure 5. General overview of the receiver operating characteristic (ROC) curve and area under the curve (AUC). 


\subsection{Fusarium Head Blight Detection Using a Multivariate Classification Approach}

After the univariate FHB monitoring models (that were developed using all features) were evaluated, a multivariate classification approach was used to develop the FHB monitoring model. In this study, a backpropagation (BP) neural network was used to develop the multivariate FHB monitoring model. The BP neural network is a multilayer feedforward neural network. In general, it has three layers: an input layer, a hidden layer, and an output layer [47]. The training process of the BP neural network follows two steps: in the first step, variables are assigned to the input layer, and the outcome is calculated through the weighted sum of the hidden layer; in the second step, the error of the outcome is transferred from the output layer to the input layer, and the weights and biases of variables are adjusted to decrease the error of the outcome. When this error is reduced to 0.1 , the training of the neural network is completed.

However, the training process of the BP neural network is a local search mechanism, and it may lead to trapping of the BP neural network in the local optimum. To avoid this problem, the simulated annealing algorithm was integrated into the BP neural network. The simulated annealing algorithm is a greedy algorithm, which lets the algorithm escape from the local optimum by accepting values that increase the error [48]. Figure 6 shows the structure of the improved BP neural network. In addition, the Akaike information criterion (AIC) was used to evaluate the complexity and accuracy of the multivariate FHB monitoring model. The AIC is a model evaluation index that comprehensively considers the number of model parameters, the number of samples, and the monitoring accuracy. The larger the AIC, the better the model [49].

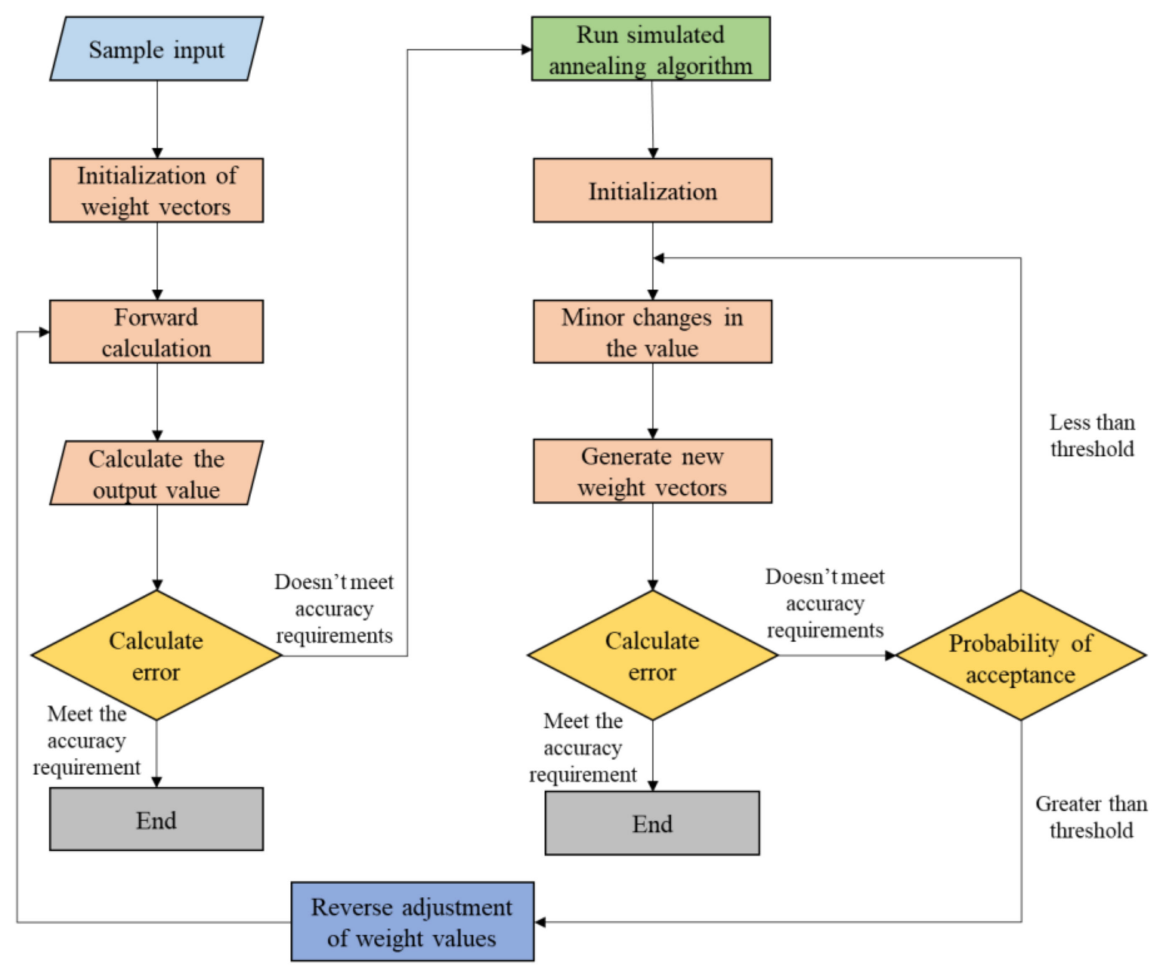

Figure 6. General overview of the improved backpropagation (BP) neural network.

In addition, five commonly used methods, including partial least square regression (PLSR), Fisher's linear discriminant analysis (FLDA), logistic regression (LR), random forests (RFs), and SVM, were compared with the improved BP neural network. The existing methods were widely utilized to monitor disease outbreaks, and Table 3 presents detailed descriptions for these. 
Table 3. Detailed descriptions of five methods used in this study.

\begin{tabular}{|c|c|c|c|}
\hline Abbreviation & Full Name & Description & Reference \\
\hline PLSR & $\begin{array}{l}\text { Partial least square } \\
\text { regression }\end{array}$ & $\begin{array}{c}\text { A statistical method that identifies a linear regression } \\
\text { model by projecting the predicted variables and the } \\
\text { observable variables to a new space. It has proven to } \\
\text { be the most widely used linear regression technique } \\
\text { for estimating soil attributes, disease severity, } \\
\text { photosynthetic capacity, etc. }\end{array}$ & {$[38,40]$} \\
\hline FLDA & $\begin{array}{c}\text { Fisher's linear } \\
\text { discriminant analysis }\end{array}$ & $\begin{array}{l}\text { A method used in statistics, pattern recognition, and } \\
\text { machine learning to identify a linear combination of } \\
\text { features that characterizes or separates two or more } \\
\text { classes of objects. In recent studies, it has been used } \\
\text { to model the relationship between spectral } \\
\text { reflectance and crop disease severity. }\end{array}$ & {$[50,51]$} \\
\hline LR & Logistic regression & $\begin{array}{l}\text { A statistical method that can be used to describe the } \\
\text { relationship between a dependent variable and } \\
\text { multiple independent variables. It is less affected by } \\
\text { the non-normality of variables. Recently, some } \\
\text { studies have found that models developed using } \\
\text { logistic regression had a better performance in } \\
\text { remote sensing monitoring of banana fusarium wilt } \\
\text { and wheat yellow rust. }\end{array}$ & {$[16,52]$} \\
\hline RFs & Random Forests & $\begin{array}{l}\text { An ensemble learning method for classification via } \\
\text { constructing a multitude of decision trees in the } \\
\text { training process and outputting the result according } \\
\text { to the predictions of individual trees. It has proven } \\
\text { to be an effective method in crop type mapping, } \\
\text { vegetation biomass estimating, etc. }\end{array}$ & {$[53,54]$} \\
\hline SVM & Support vector machine & $\begin{array}{c}\text { A supervised learning model that divides the } \\
\text { examples of separate categories by a clear gap that } \\
\text { should be as wide as possible. It has been used in } \\
\text { wheat yellow rust detection, wheat powdery mildew } \\
\text { monitoring, etc. }\end{array}$ & {$[55,56]$} \\
\hline
\end{tabular}

\section{Results}

\subsection{Evaluation of the Univariate Monitoring Model}

Table 4 shows the AUC and corresponding standard deviation (Std) of the univariate FHB monitoring model developed using features. Table 4 shows the first five original spectral bands with better performances, and the sensitivity and specificity of the optimal threshold of each feature were also included. In general, the modified chlorophyll absorption reflectance index (MCARI) performed best among all features with AUC and Std values of 1.0 and 0.0, respectively. Band 50 (650 nm) and Band $60(690 \mathrm{~nm})$ had the same AUC and Std, whereas the specificity of Band $50(650 \mathrm{~nm})$ was higher than that of Band $60(690 \mathrm{~nm})$. Texture features had moderate performances compared with other features, and they had the highest Std.

Figure 7 shows the optimal thresholds and values of samples of the univariate FHB monitoring model. The yellow dots represent slightly diseased samples, red dots represent severely diseased samples, and the black dotted line indicates the optimal threshold. For features with higher AUC, sensitivity, and specificity (i.e., MCARI), two types of samples were more separable. In contrast, for features with lower AUC, sensitivity, and specificity (i.e., $\operatorname{LBP}_{(8,1)}$ ), two types of samples were difficult to separate. Moreover, a number of features had similar optimal thresholds, such as Band $50(650 \mathrm{~nm})$ and Band $55(670 \mathrm{~nm})$. This may be because of the similar spectral reflectance of the wheat canopy in 650 and $670 \mathrm{~nm}$. 
Table 4. Evaluation results of the univariate monitoring model.

\begin{tabular}{|c|c|c|c|c|c|}
\hline & & Mean AUC & Std & Sens. & Spec. \\
\hline \multirow{5}{*}{ Spectral bands } & Band $50(650 \mathrm{~nm})$ & 0.99 & 0.01 & 0.94 & 0.98 \\
\hline & Band $55(670 \mathrm{~nm})$ & 0.98 & 0.01 & 0.90 & 1.00 \\
\hline & Band $60(690 \mathrm{~nm})$ & 0.99 & 0.01 & 0.94 & 0.94 \\
\hline & Band $70(730 \mathrm{~nm})$ & 0.92 & 0.03 & 0.88 & 0.84 \\
\hline & Band $80(770 \mathrm{~nm})$ & 0.82 & 0.04 & 0.82 & 0.74 \\
\hline \multirow{11}{*}{ Vegetation indexes } & PRI & 0.19 & 0.04 & - & - \\
\hline & PhRI & 0.06 & 0.02 & - & - \\
\hline & NRI & 0.67 & 0.05 & 0.52 & 0.86 \\
\hline & NDVI & 0.07 & 0.02 & - & - \\
\hline & MSR & 0.07 & 0.02 & - & - \\
\hline & MCARI & 1.00 & 0.00 & 0.98 & 1.00 \\
\hline & GI & 0.75 & 0.05 & 0.58 & 0.84 \\
\hline & TVI & 0.73 & 0.05 & 0.86 & 0.50 \\
\hline & TCARI & 0.76 & 0.05 & 0.76 & 0.76 \\
\hline & RVSI & 0.21 & 0.05 & - & - \\
\hline & PSRI & 0.29 & 0.05 & - & - \\
\hline \multirow{3}{*}{ Texture features } & $\operatorname{LBP}_{(8,1)}$ & 0.40 & 0.06 & 0.18 & 0.94 \\
\hline & $\operatorname{LBP}_{(8,2)}$ & 0.47 & 0.06 & 0.22 & 0.92 \\
\hline & $\operatorname{LBP}_{(16,2)}$ & 0.40 & 0.06 & 0.12 & 0.94 \\
\hline
\end{tabular}

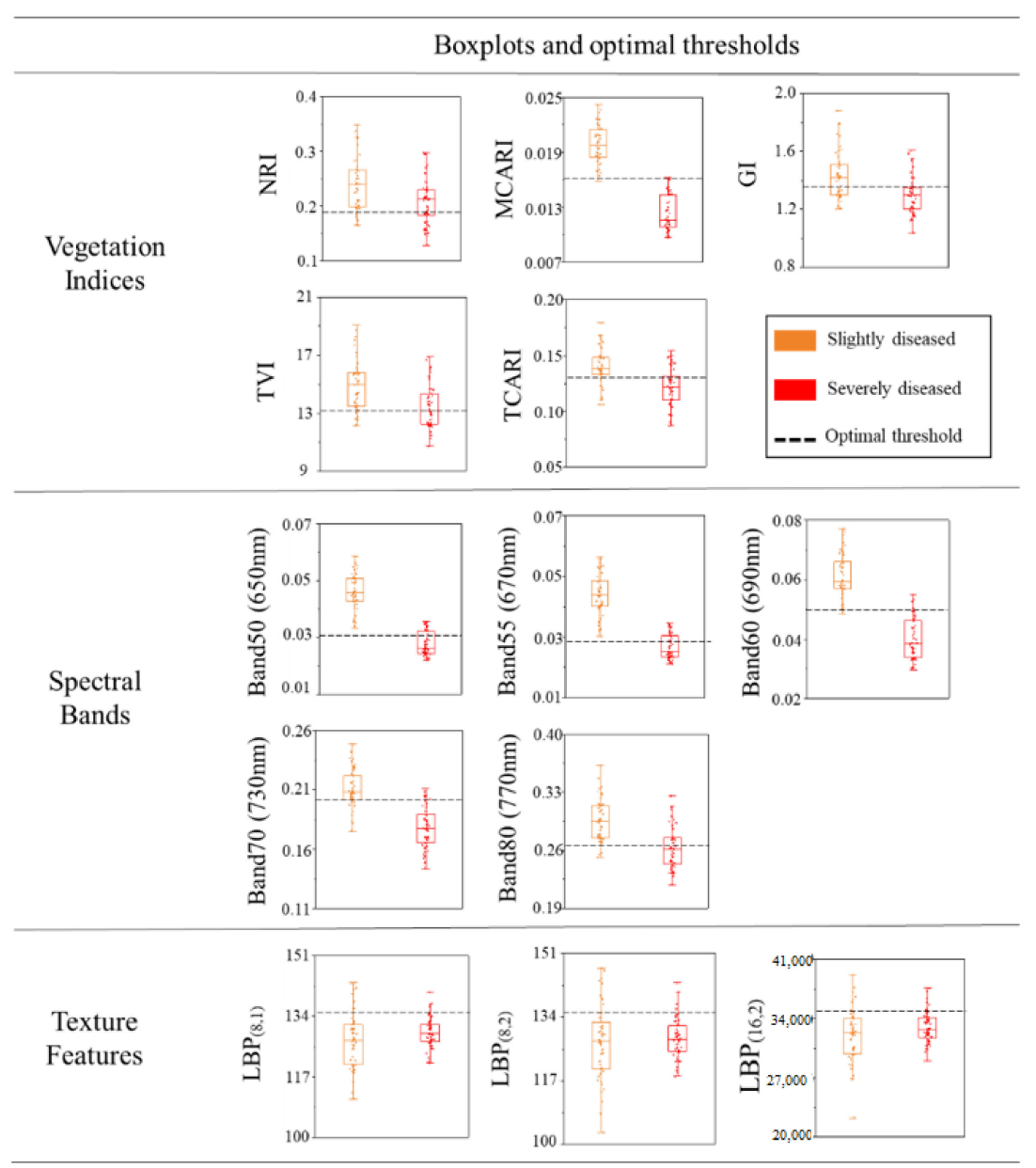

Figure 7. Optimal thresholds and values of samples for the univariate monitoring model. 


\subsection{Evaluation of the Multivariate Monitoring Model}

When developing the multivariate FHB monitoring model using an improved BP neural network, all features in Section 3.1 were used as input first. These include five original spectral bands, 11 vegetation indexes, and three texture features. Then, backward feature selection was used to filter these features. Table 5 shows the features and AIC values of the multivariate FHB monitoring model before and after backward feature selection. Only seven of 19 original features remained after backward feature selection, and the AIC of the multivariate FHB monitoring model decreased from -362.3 to -500.64 , indicating systematic improvement of the power of explanation. It should be noted that the modified simple ratio (MSR) performed worse in Section 3.1 (with AUC of 0.07) while it was contained in the feature set after backward feature selection. The reason was that the MSR contained useful information for FHB monitoring and realized a complementing effect with other features.

Table 5. Feature variables and Akaike information criterion (AIC) of the models before and after backward feature selection.

\begin{tabular}{|c|c|c|c|}
\hline Type of Model & List of Variables & Parameter & Value \\
\hline \multirow[b]{2}{*}{ Model with all features } & \multirow{2}{*}{$\begin{array}{c}\text { PRI + PhRI + NRI + NDVI + MSR + MCARI + GI + TVI + } \\
\text { TCARI + RVSI + PSRI + Band } 50(650 \mathrm{~nm})+\text { Band } 55(670 \mathrm{~nm}) \\
+ \text { Band } 60(690 \mathrm{~nm})+\text { Band } 70(730 \mathrm{~nm})+\text { Band } 80(770 \mathrm{~nm})+ \\
\operatorname{LBP}_{(8,1)}+\mathrm{LBP}_{(8,2)}+\mathrm{LBP}_{(16,2)}\end{array}$} & Mean AIC & -362.30 \\
\hline & & $\begin{array}{l}\text { Number of } \\
\text { variables }\end{array}$ & 19 \\
\hline \multirow{3}{*}{ Model with simplified features } & \multirow{3}{*}{$\begin{array}{c}\mathrm{NRI}+\mathrm{MCARI}+\mathrm{MSR}+\mathrm{GI}+\mathrm{TVI}+\mathrm{LBP}_{(8,2)} \\
+ \text { Band } 50(650 \mathrm{~nm})\end{array}$} & Mean AIC & -500.64 \\
\hline & & $\begin{array}{l}\text { Number of } \\
\text { variables }\end{array}$ & 7 \\
\hline & & $\begin{array}{c}\text { Gain }(\% \text { AIC } \\
\text { reduction) }\end{array}$ & 38.1 \\
\hline
\end{tabular}

The test set was used to evaluate the performance of models developed using the improved BP neural network, PLSR, FLDA, LR, RFs and SVM, and the test results were exhibited in the form of a confusion matrix (Table 6). This confusion matrix, also known as an error matrix, is a matrix with two rows and two columns. Values of producer accuracy, user accuracy, overall accuracy, and Kappa coefficient were applied to the confusion matrix. The overall accuracy indicated the general classification performance of the classifier on the test set. The Kappa coefficient was used to quantify the consistency between the real classes and classification results of samples. The producer accuracy represents the number of classified reference samples that were accurately divided by the total number of reference samples for that class. The user accuracy was calculated by dividing the total number of correct classifications for a particular class and by the row total. Table 6 shows that the FHB monitoring model that was developed using an improved BP neural network achieved the highest overall accuracy of $98 \%$. Moreover, the difference of producer accuracy and user accuracy of the improved BP neural network was smallest among all models, indicating that this model had superior stability. With regard to the models that were developed using five commonly used methods, FLDA, RFs, and SVM achieved the same overall accuracies. However, the difference of producer accuracy and user accuracy in FLDA was larger than in the other two methods. The higher producer accuracy of severely diseased samples of FLDA indicated that it tended to misclassify slightly diseased samples as severely diseased samples. LR had the lowest overall accuracy, producer accuracy, and user accuracy, indicating that it performed worst in distinguishing between slightly and severely diseased wheat canopies. 
Table 6. Overall verification results of five commonly used algorithms and improved BP neural network.

\begin{tabular}{|c|c|c|c|c|c|c|c|}
\hline & & \multicolumn{3}{|c|}{ Reference } & \multirow[b]{2}{*}{$\begin{array}{c}\text { User } \\
\text { Accuracy (\%) }\end{array}$} & \multirow[b]{2}{*}{$\begin{array}{c}\text { Overall } \\
\text { Accuracy (\%) }\end{array}$} & \multirow[b]{2}{*}{ Kappa } \\
\hline & & $\begin{array}{c}\text { Slightly } \\
\text { Diseased }\end{array}$ & $\begin{array}{l}\text { Severely } \\
\text { Diseased }\end{array}$ & Sum & & & \\
\hline \multirow{4}{*}{$\begin{array}{l}\text { Improved BP } \\
\text { neural network }\end{array}$} & Slightly diseased & 49 & 1 & 50 & 98 & \multirow{4}{*}{98} & \multirow{4}{*}{0.96} \\
\hline & Severely diseased & 1 & 49 & 50 & 98 & & \\
\hline & Sum & 50 & 50 & 100 & & & \\
\hline & Producer accuracy (\%) & 98 & 98 & & & & \\
\hline \multirow{4}{*}{ PLSR } & Slightly diseased & 45 & 4 & 49 & 92 & \multirow{4}{*}{91} & \multirow{4}{*}{0.82} \\
\hline & Severely diseased & 5 & 46 & 51 & 90 & & \\
\hline & Sum & 50 & 50 & 100 & & & \\
\hline & Producer accuracy $(\%)$ & 90 & 92 & & & & \\
\hline \multirow{4}{*}{ FLDA } & Slightly diseased & 45 & 0 & 45 & 100 & \multirow{4}{*}{95} & \multirow{4}{*}{0.9} \\
\hline & Severely diseased & 5 & 50 & 55 & 91 & & \\
\hline & Sum & 50 & 50 & 100 & & & \\
\hline & Producer accuracy $(\%)$ & 90 & 100 & & & & \\
\hline \multirow{4}{*}{ LR } & Slightly diseased & 45 & 5 & 50 & 90 & \multirow{4}{*}{90} & \multirow{4}{*}{0.8} \\
\hline & Severely diseased & 5 & 45 & 50 & 90 & & \\
\hline & Sum & 50 & 50 & 100 & & & \\
\hline & Producer accuracy (\%) & 90 & 90 & & & & \\
\hline \multirow{4}{*}{ RFs } & Slightly diseased & 46 & 1 & 47 & 98 & \multirow{4}{*}{95} & \multirow{4}{*}{0.9} \\
\hline & Severely diseased & 4 & 49 & 53 & 92 & & \\
\hline & Sum & 50 & 50 & 100 & & & \\
\hline & Producer accuracy $(\%)$ & 92 & 98 & & & & \\
\hline \multirow{4}{*}{ SVM } & Slightly diseased & 46 & 1 & 47 & 98 & \multirow{4}{*}{95} & \multirow{4}{*}{0.9} \\
\hline & Severely diseased & 4 & 49 & 53 & 92 & & \\
\hline & Sum & 50 & 50 & 100 & & & \\
\hline & Producer accuracy (\%) & 92 & 98 & & & & \\
\hline
\end{tabular}

Based on the overall verification results shown in Table 6, the model developed using the improved BP neural network was chosen to monitor the severity of wheat canopy effects in the experimental field. The monitoring result is shown in Figure 8.

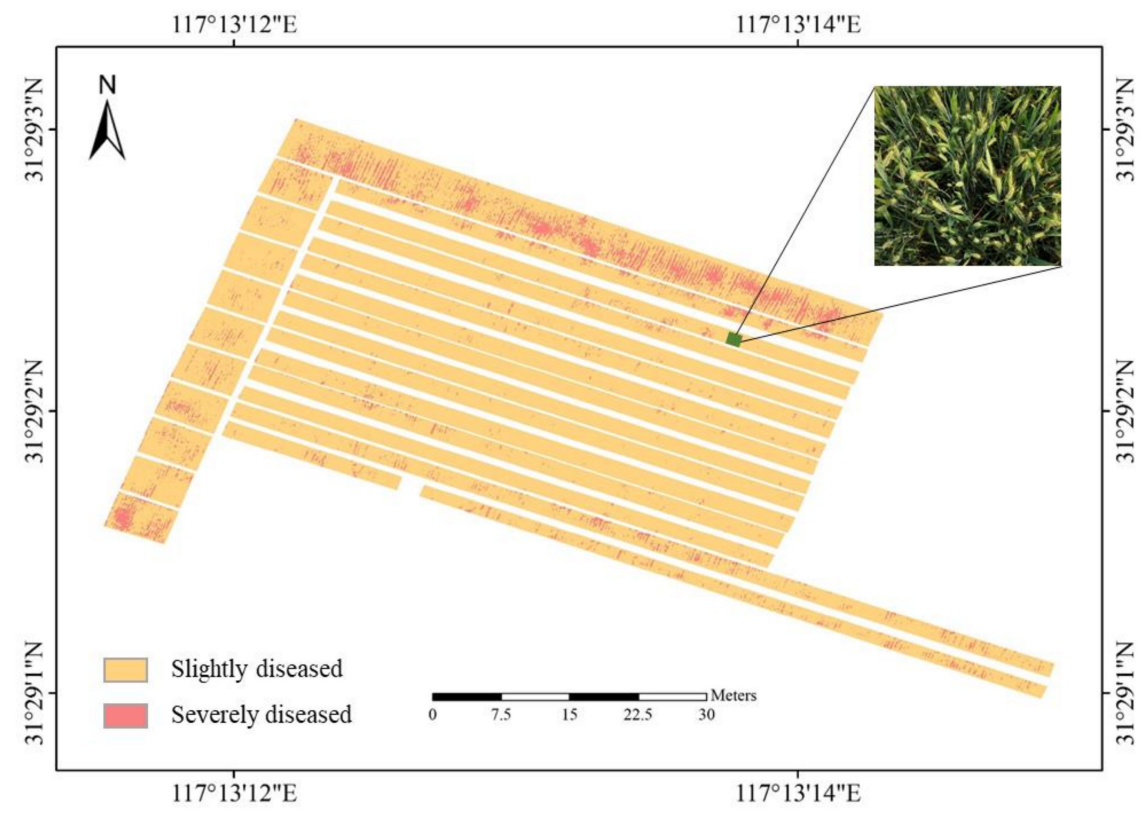

(a)

Figure 8. Cont. 


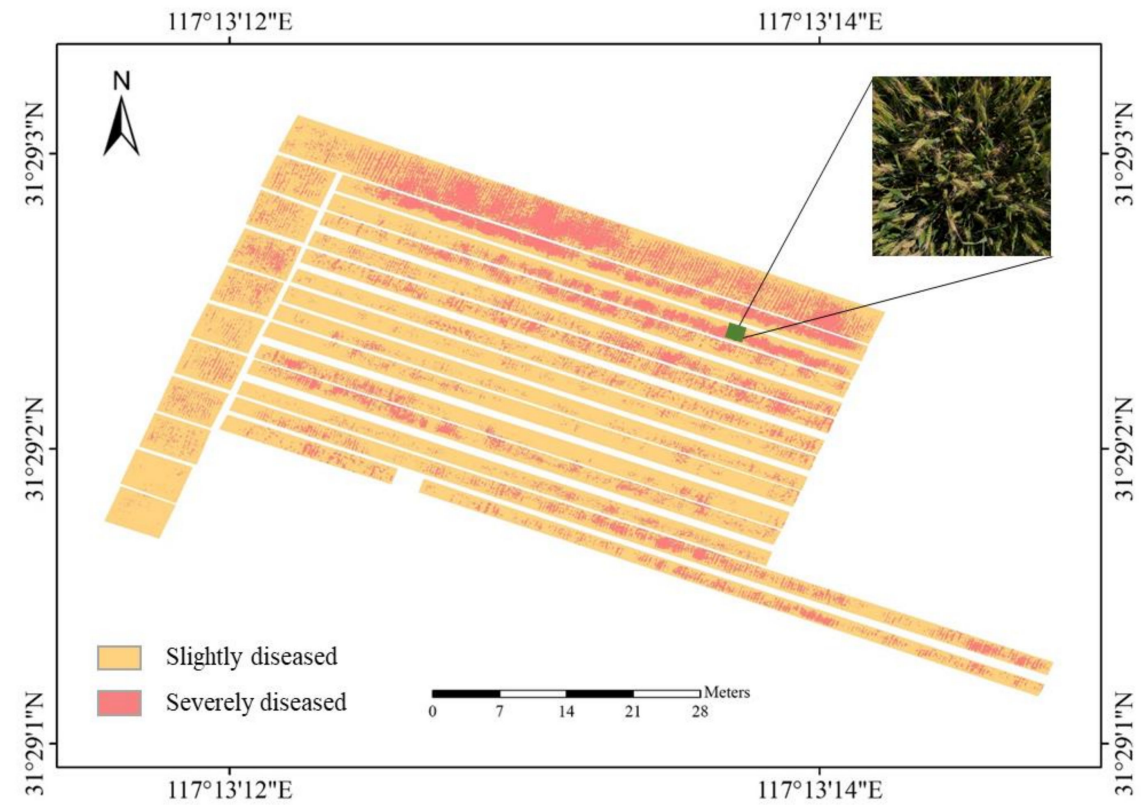

(b)

Figure 8. The monitoring result of wheat Fusarium head blight (FHB) using the improved BP neural network. (a) FHB monitoring result for 3 May 2019, and (b) FHB monitoring result for 8 May 2019. The yellow color represents slightly FHB-infected wheat canopies, and the red color represents severely FHB-infected wheat canopies. The photos in $(\mathbf{a}, \mathbf{b})$ on the right are canopy photos of the sample plot.

\section{Discussion}

Hyperspectral images from UAVs have been used to monitor vegetation pests and diseases in many studies. Some people tried to detect pests in vineyards by combining UAV hyperspectral images with ground data. The vegetation indexes that were sensitive to the pest were calculated, and the pest monitoring model was developed based on these indexes [57]. The approach proposed in this study also combined the UAV hyperspectral imagery with ground survey data. Considering that wheat FHB could change the structure and shape of a wheat canopy, this study added texture features to the spectral features as inputs for the monitoring model. There has also been some research attempting to apply deep learning to monitor pests and diseases using UAV hyperspectral imagery $[26,58,59]$. The monitoring accuracies achieved in these studies were generally high, but the poor interpretability of the extracted features makes it difficult to apply the model to other regions. This study combined plant pathology and remote sensing disease monitoring mechanisms to select the features, and the proposed model can be easily applied to areas that are similar to the experimental field.

Early attempts were made to apply remote sensing techniques to the monitoring of wheat FHB [60]. However, given the demands of production, most of the research only applied remote sensing technology to detect FHB in wheat kernels $[61,62]$. These studies attempted to extract the spectral characteristics of diseased wheat kernels through spectral indices, principal component transformations, and other methods, and thus constructed monitoring models. Consistently with these studies, different vegetation indices exhibited different traits when monitoring FHB in this paper. In recent years, some studies attempted to identify diseased areas of spikelet through multispectral or hyperspectral images taken in wheat fields $[8,63,64]$. They found that the wavelengths near $650 \mathrm{~nm}$ were sensitive to wheat FHB, which is consistent with the findings of this study. However, the target areas of these studies were small, and the models constructed did not meet the need for accurate monitoring of wheat FHB in a wheat field. This study combined spectral and textural features to construct a model for the monitoring of FHB at field scale, extending the previous models in terms of feature types and monitoring area. It is worth noting that, in this study, univariate monitoring 
models developed using texture features had moderate mean AUCs; this may be largely due to the lower spatial resolution of images, and this also indicated that utilizing texture features alone for FHB monitoring at the field scale is not sufficient.

The combination of the simulated annealing algorithm and BP neural network has been used in many remote sensing applications, such as air quality prediction, traffic flow forecasting, rock mass parameter prediction, etc. [65-68]. These studies found that the model constructed by this method was able to achieve higher monitoring accuracy than the BP neural network. In this study, the improved BP neural network performed better than five commonly used algorithms. The producer accuracy and user accuracy of the improved BP neural network in slightly and severely diseased samples exceeded 95\%, and kappa was 0.96. This superior performance of the improved BP neural network was likely the result of two features. The relationship between features (i.e., original spectral bands, vegetation indices, and texture features) and the severity of FHB was complex, and the improved BP neural network has the ability to generate complex decision boundaries in the feature space. In addition, the improved BP neural network was proposed by integrating a simulated annealing algorithm into the BP neural network. Therefore, it could avoid becoming trapped in the local optimum, and offers the advantages of the BP neural network to effectively avoid overfitting of the data.

In Section 3.2, the improved BP neural network was used to monitor the severity of FHB infection of wheat canopies in the experimental field, and the monitoring results of 3 and 8 May are shown in Figure 5. It was obvious that the area of severely diseased wheat canopies increased rapidly from 3-8 May. Considering that no measures had been taken to prevent FHB in the experimental field, the conclusion can be drawn that the spreading of Fusarium graminearum would be rapid if no preventive measures were taken at the grain filling stage.

Although this study yielded satisfactory results for wheat FHB monitoring, there are still some weaknesses that need to be improved in future research. First, the number of plots was small in this study due to the high cost in the process of plot data collection. The small plot size led to the lack of a model validation process based on real independent data. Limited training data are a common problem in remote sensing applications [56], and many approaches have been used to mitigate small training samples, including data augmentation, unsupervised training, and transfer learning [69]. Future research could attempt to use these methods to overcome the problem of small plots and thus develop a more stable and efficient monitoring model. Second, the monitoring model proposed in this study is a binary classification approach based on multiple features. In order to make the monitoring results more instructive, future studies could assess the uncertainty of classification and improve the model based on the characteristics of the pixels with greater uncertainty.

In addition, a number of limitations and challenges still remain when applying the proposed approach in monitoring wheat FHB. Firstly, the crop cultivars, cultivation procedures, and management practices of the experimental field were uniform. When the proposed approach is applied to wheat fields with different wheat cultivars, cultivation procedures, or management practices, the features that performed well in this study may not be applicable. However, the idea of wheat FHB monitoring based on spectral and textural features is still valid. Future research could validate the proposed approach in wheat fields with different wheat cultivars, cultivation procedures, or management practices. Secondly, FHB was the only disease of wheat in this experimental field; thus, it remains unclear whether the features used in this study (i.e., original spectral bands, vegetation indexes, and texture features) are effective for monitoring the severity of FHB in cases where this disease is accompanied by other wheat diseases. Thirdly, it is not clear whether this approach will perform well when distinguishing slightly and severely infected wheat canopies from other vegetation and non-vegetation classes. Future research could evaluate the ability of this approach in distinguishing wheat from other classes. In addition, the hyperspectral images from the UAV and field plots were acquired at the grain filling stage; thus, the performance of the multivariate FHB monitoring model at other stages of the FHB infection needs to be evaluated by future research. 
In this study, the hyperspectral images from a UAV were used to monitor the severity of FHB. Many studies have attempted to use RGB images for detection of wheat FHB because UAV RGB imagery has advantages in terms of cost and coverage [70-72]. However, Dammer et al. (2011) found that bands other than red, green, and blue contain some useful information for FHB monitoring [73]. Moreover, when the symptoms are completely exhibited, the observation of FHB is too late for preventative measurement. Therefore, it is important to detect FHB in the early stages. The symptoms are hard to observe in the RGB images in the early stages, though acquiring rich spectral information on the wheat canopy is more important for FHB monitoring. Future research could compare the performance of UAV RGB images and UAV hyperspectral images on the monitoring of FHB in different stages. Currently, UAV imagery is suitable for FHB monitoring in a smaller area, while satellite imagery would be more appropriate when carrying out FHB monitoring in large areas. However, when monitoring FHB in large areas, due to the lower spatial resolution of satellite imagery and large regional variation, some natural and economic factors, such as temperature, humidity, and management practices, do have a significant impact on the occurrence of the disease. It could be useful to extract these factors when monitoring the occurrence of the disease in large area.

\section{Conclusions}

Hyperspectral images from UAVs offer valuable and reliable data for wheat FHB monitoring in the field. This study achieved accurate monitoring of wheat FHB by utilizing spectral features and texture features of UAV hyperspectral images. After obtaining hyperspectral images, three types of features (including original spectral bands, vegetation indexes, and texture features) were extracted. Based on these features, univariate FHB monitoring models were developed to evaluate the ability of each feature to identify different levels of severity of wheat FHB. Then, the multivariate FHB monitoring model using an improved BP neural network was developed based on the most sensitive features. To decrease the complexity and avoid overfitting of the model, a backward feature selection was applied before model development. Five commonly used methods (i.e., PLSR, FLDA, LR, RFs, and SVM) were used to establish the monitoring model, and the results were compared with those of the improved BP neural network. This comparison showed that the improved BP neural network performed best among all tested models, with overall accuracy of $98 \%$ and kappa of 0.96 . This study provides a reference for wheat FHB monitoring via hyperspectral UAV images. The approach proposed in this study extends the previous models in terms of feature types and monitoring area. However, the limited plots have some effects on model development and validation. Future research could attempt to use data augmentation, unsupervised training, and transfer learning to overcome the problem. Moreover, future research should explore the performance of this method in fields with different wheat cultivars, in fields with multiple diseases, and in fields with wheat at other growth stages. In addition, more features (such as soil type, cultivation procedures, and management practices) should be considered in future research to develop a more robust and more reliable wheat FHB monitoring model.

Author Contributions: Data curation, L.L.; Formal analysis, Y.D., X.D., and H.M.; Funding acquisition, Y.D. and W.H.; Investigation, X.D. and H.M.; Methodology, L.L. and X.D.; Resources, W.H.; Writing—original draft, L.L. All authors have read and agreed to the published version of the manuscript.

Funding: This work was supported in part by the National Key Research and Development Program of China under Grants 2017YFE0122400 and 2016YFD0300601, in part by the National Natural Science Foundation of China 42071423, and in part by the National Key R\&D Program of China 2016YFD0300702, Youth Innovation Promotion Association CAS (2017085), Beijing Nova Program of Science and Technology (Z191100001119089), and Special Fund for Basic Scientific Research Project in the Central Scientific Research Institutes (Institute of Grassland Research of CAAS) (1610332020026).

Conflicts of Interest: The authors declare no conflict of interest. 


\section{References}

1. Mutanga, O.; Dube, T.; Galal, O. Remote sensing of crop health for food security in Africa: Potentials and constraints. Remote Sens. Appl. Soc. Environ. 2017, 8, 231-239. [CrossRef]

2. Rojas, E.C.; Sapkota, R.; Jensen, B.; Jørgensen, H.J.L.; Henriksson, T.; Jørgensen, L.N.; Nicolaisen, M.; Collinge, D.B. Fusarium Head Blight Modifies Fungal Endophytic Communities During Infection of Wheat Spikes. Microb. Ecol. 2020, 79, 397-408. [CrossRef] [PubMed]

3. Ma, Z.; Xie, Q.; Li, G.; Jia, H.; Zhou, J.; Kong, Z.; Li, N.; Yuan, Y. Germplasms, genetics and genomics for better control of disastrous wheat Fusarium head blight. Theor. Appl. Genet. 2020, 133, 1541-1568. [CrossRef] [PubMed]

4. Drakopoulos, D.; Kägi, A.; Gimeno, A.; Six, J.; Jenny, E.; Forrer, H.-R.; Musa, T.; Meca, G.; Vogelgsang, S. Prevention of Fusarium head blight infection and mycotoxins in wheat with cut-and-carry biofumigation and botanicals. Field Crop. Res. 2020, 246, 107681. [CrossRef]

5. Bauriegel, E.; Herppich, W.B. Hyperspectral and Chlorophyll Fluorescence Imaging for Early Detection of Plant Diseases, with Special Reference to Fusarium spec. Infections on Wheat. Agriculture 2014, 4, 32-57. [CrossRef]

6. Huang, L.; Li, T.; Ding, C.; Zhao, J.; Zhang, D.; Yang, G. Diagnosis of the Severity of Fusarium Head Blight of Wheat Ears on the Basis of Image and Spectral Feature Fusion. Sensors 2020, 20, 2887. [CrossRef]

7. Zhang, J.; Huang, Y.; Pu, R.; Gonzalez-Moreno, P.; Yuan, L.; Wu, K.; Huang, W. Monitoring plant diseases and pests through remote sensing technology: A review. Comput. Electron. Agric. 2019, 165, 104943. [CrossRef]

8. Jin, X.; Jie, L.; Wang, S.; Qi, H.J.; Li, S.W. Classifying Wheat Hyperspectral Pixels of Healthy Heads and Fusarium Head Blight Disease Using a Deep Neural Network in the Wild Field. Remote Sens. 2018, 10, 395. [CrossRef]

9. Zhang, N.; Pan, Y.; Feng, H.; Zhao, X.; Yang, X.; Ding, C.; Yang, G. Development of Fusarium head blight classification index using hyperspectral microscopy images of winter wheat spikelets. Biosyst. Eng. 2019, 186, 83-99. [CrossRef]

10. Zhang, D.-Y.; Chen, G.; Yin, X.; Hu, R.-J.; Gu, C.-Y.; Pan, Z.-G.; Zhou, X.; Chen, Y. Integrating spectral and image data to detect Fusarium head blight of wheat. Comput. Electron. Agric. 2020, 175, 105588. [CrossRef]

11. Li, B.; Xu, X.; Zhang, L.; Han, J.; Bian, C.; Li, G.; Liu, J.; Jin, L. Above-ground biomass estimation and yield prediction in potato by using UAV-based RGB and hyperspectral imaging. ISPRS J. Photogramm. Remote Sens. 2020, 162, 161-172. [CrossRef]

12. Zarco-Tejada, P.J.; Guillén-Climent, M.L.; Hernández-Clemente, R.; Catalina, A.; Gonzalez, M.R.; Martin, P.R. Estimating leaf carotenoid content in vineyards using high resolution hyperspectral imagery acquired from an unmanned aerial vehicle (UAV). Agric. For. Meteorol. 2013, 171, 281-294. [CrossRef]

13. Zheng, H.; Ma, J.; Zhou, M.; Li, D.; Yao, X.; Cao, W.; Zhu, Y.; Cheng, T. Enhancing the Nitrogen Signals of Rice Canopies across Critical Growth Stages through the Integration of Textural and Spectral Information from Unmanned Aerial Vehicle (UAV) Multispectral Imagery. Remote Sens. 2020, 12, 957. [CrossRef]

14. Guo, Y.; Wang, H.; Wu, Z.; Wang, S.; Sun, H.; Senthilnath, J.; Wang, J.; Bryant, C.R.; Fu, Y.H. Modified Red Blue Vegetation Index for Chlorophyll Estimation and Yield Prediction of Maize from Visible Images Captured by UAV. Sensors 2020, 20, 5055. [CrossRef] [PubMed]

15. Ma, H.; Huang, W.; Jing, Y.; Pignatti, S.; Laneve, G.; Dong, Y.; Ye, H.; Liu, L.; Guo, A.; Jiang, J. Identification of Fusarium Head Blight in Winter Wheat Ears Using Continuous Wavelet Analysis. Sensors 2019, $20,20$. [CrossRef] [PubMed]

16. Ye, H.; Huang, W.; Huang, S.; Cui, B.; Dong, Y.; Guo, A.; Ren, Y.; Jin, Y. Recognition of Banana Fusarium Wilt Based on UAV Remote Sensing. Remote Sens. 2020, 12, 938. [CrossRef]

17. Yan, Z.; Zhang, H.; Van Der Lee, T.; Waalwijk, C.; Van Diepeningen, A.; Deng, Y.; Feng, J.; Liu, T.; Chen, W. Resistance to Fusarium head blight and mycotoxin accumulation among 129 wheat cultivars from different ecological regions in China. World Mycotoxin J. 2020, 13, 189-200. [CrossRef]

18. Daryaei, A.; Sohrabi, H.; Atzberger, C.; Immitzer, M. Fine-scale detection of vegetation in semi-arid mountainous areas with focus on riparian landscapes using Sentinel-2 and UAV data. Comput. Electron. Agric. 2020, 177, 105686. [CrossRef]

19. Hagen, N.; Kudenov, M.W. Review of snapshot spectral imaging technologies. Opt. Eng. 2013, 52, 090901. [CrossRef] 
20. Song, B.; Park, K.-H. Detection of Aquatic Plants Using Multispectral UAV Imagery and Vegetation Index. Remote Sens. 2020, 12, 387. [CrossRef]

21. Wu, D.; Phinn, S.; Phinn, S.; Robson, A.; Johansen, K. Optimising drone flight planning for measuring horticultural tree crop structure. ISPRS J. Photogramm. Remote Sens. 2020, 160, 83-96. [CrossRef]

22. Ishida, T.; Kurihara, J.; Viray, F.A.; Namuco, S.B.; Paringit, E.C.; Perez, G.J.; Takahashi, Y.; Marciano, J.J. A novel approach for vegetation classification using UAV-based hyperspectral imaging. Comput. Electron. Agric. 2018, 144, 80-85. [CrossRef]

23. Song, P.; Zheng, X.; Li, Y.; Zhang, K.; Huang, J.; Li, H.; Zhang, H.; Liu, L.; Wei, C.; Mansaray, L.R.; et al. Estimating reed loss caused by Locusta migratoria manilensis using UAV-based hyperspectral data. Sci. Total Environ. 2020, 719, 137519. [CrossRef] [PubMed]

24. Ivushkin, K.; Bartholomeus, H.; Bregt, A.K.; Pulatov, A.; Franceschini, M.H.D.; Kramer, H.; Van Loo, E.N.; Roman, V.J.; Finkers, R. UAV based soil salinity assessment of cropland. Geoderma 2019, 338, 502-512. [CrossRef]

25. Zhang, N.; Zhang, X.; Yang, G.; Zhu, C.; Huo, L.; Feng, H. Assessment of defoliation during the Dendrolimus tabulaeformis Tsai et Liu disaster outbreak using UAV-based hyperspectral images. Remote Sens. Environ. 2018, 217, 323-339. [CrossRef]

26. Abdulridha, J.; Ampatzidis, Y.; Roberts, P.D.; Kakarla, S.C. Detecting powdery mildew disease in squash at different stages using UAV-based hyperspectral imaging and artificial intelligence. Biosyst. Eng. 2020, 197, 135-148. [CrossRef]

27. Yuan, L.; Yan, P.; Wen-Yan, H.; Huang, Y.; Wang, B.; Zhang, J.; Zhang, H.; Bao, Z. Detection of anthracnose in tea plants based on hyperspectral imaging. Comput. Electron. Agric. 2019, 167, 105039. [CrossRef]

28. Huang, W.; Lamb, D.W.; Niu, Z.; Zhang, Y.; Liu, L.; Wang, J. Identification of yellow rust in wheat using in-situ spectral reflectance measurements and airborne hyperspectral imaging. Precis. Agric. 2007, 8, 187-197. [CrossRef]

29. Shan, C.; Wang, W.; Liu, C.; Sun, Y.; Hu, Q.; Xu, X.; Tian, Y.; Zhang, H.; Morino, I.; Griffith, D.W.; et al. Regional CO emission estimated from ground-based remote sensing at Hefei site, China. Atmos. Res. 2019, 222, 25-35. [CrossRef]

30. Tao, X.; Cui, J.; Dai, Y.; Wang, Z.; Xu, X. Soil respiration responses to soil physiochemical properties in urban different green-lands: A case study in Hefei, China. Int. Soil Water Conserv. Res. 2016, 4, 224-229. [CrossRef]

31. Li, W.; Liu, Y.; Chen, H.; Zhang, C.C. Estimation model of winter wheat disease based on meteorological factors and spectral information. Food Prod. Process. Nutr. 2020, 2, 1-7. [CrossRef]

32. Shuping, Y.; Hanyi, L.; Afeng, W. Coupling Induction of Wheat Scab, Gibberella zeae. Plant Dis. Pests 2017, 8, 34-36.

33. Devadas, R.; Lamb, D.; Simpfendorfer, S.; Backhouse, D. Evaluating ten spectral vegetation indices for identifying rust infection in individual wheat leaves. Precis. Agric. 2008, 10, 459-470. [CrossRef]

34. Zheng, Q.; Huang, W.; Cui, X.; Dong, Y.; Huang, W.; Ma, H.; Liu, L. Identification of Wheat Yellow Rust Using Optimal Three-Band Spectral Indices in Different Growth Stages. Sensors 2018, 19, 35. [CrossRef]

35. Su, J.; Liu, C.; Hu, X.; Chen, W.-H.; Guo, L.; Chen, W.-H. Spatio-temporal monitoring of wheat yellow rust using UAV multispectral imagery. Comput. Electron. Agric. 2019, 167, 105035. [CrossRef]

36. Huang, L.; Zhang, H.; Ruan, C.; Huang, W.; Hu, T.; Zhao, J. Detection of scab in wheat ears using in situ hyperspectral data and support vector machine optimized by genetic algorithm. Int. J. Agric. Biol. Eng. 2020, 13, 182-188. [CrossRef]

37. Yuan, L.; Zhang, J.; Wang, J. Research progress of crop diseases and pests monitoring based on remote sensing. Trans. Chin. Soc. Agric. Eng. 2012, 28,1-11.

38. Yuan, L.; Huang, Y.; Loraamm, R.W.; Nie, C.; Wang, J.; Zhang, J. Spectral analysis of winter wheat leaves for detection and differentiation of diseases and insects. Field Crop. Res. 2014, 156, 199-207. [CrossRef]

39. Cao, X.; Luo, Y.; Zhou, Y.; Fan, J.; Xu, X.; West, J.S.; Duan, X.; Cheng, D. Detection of Powdery Mildew in Two Winter Wheat Plant Densities and Prediction of Grain Yield Using Canopy Hyperspectral Reflectance. PLoS ONE 2015, 10, e0121462. [CrossRef]

40. Huang, W.; Lu, J.; Ye, H.; Kong, W.; Mortimer, A.H.; Huang, W. Quantitative identification of crop disease and nitrogen-water stress in winter wheat using continuous wavelet analysis. Int. J. Agric. Biol. Eng. 2018, 11, 145-152. [CrossRef] 
41. Shi, Y.; Huang, W.; Luo, J.; Huang, L.; Zhou, X. Detection and discrimination of pests and diseases in winter wheat based on spectral indices and kernel discriminant analysis. Comput. Electron. Agric. 2017, 141, 171-180. [CrossRef]

42. Zheng, Q.; Huang, W.; Cui, X.; Huang, W.; Liu, L. New Spectral Index for Detecting Wheat Yellow Rust Using Sentinel-2 Multispectral Imagery. Sensors 2018, 18, 868. [CrossRef] [PubMed]

43. Liu, L.; Dong, Y.; Huang, W.; Du, X.; Ren, B.; Huang, L.; Zheng, Q.; Ma, H. A Disease Index for Efficiently Detecting Wheat Fusarium Head Blight Using Sentinel-2 Multispectral Imagery. IEEE Access 2020, 8, 52181-52191. [CrossRef]

44. Guo, Z.; Zhang, L.; Zhang, D. A Completed Modeling of Local Binary Pattern Operator for Texture Classification. IEEE Trans. Image Process. 2010, 19, 1657-1663. [CrossRef]

45. Yuan, L.; Pu, R.; Zhang, J.; Wang, J.; Yang, H. Using high spatial resolution satellite imagery for mapping powdery mildew at a regional scale. Precis. Agric. 2016, 17, 332-348. [CrossRef]

46. Albetis, J.; Duthoit, S.; Guttler, F.N.; Jacquin, A.; Goulard, M.; Poilvé, H.; Feret, J.-B.; Dedieu, G. Detection of Flavescence dorée Grapevine Disease Using Unmanned Aerial Vehicle (UAV) Multispectral Imagery. Remote Sens. 2017, 9, 308. [CrossRef]

47. Wang, Y.; Niu, D.; Ji, L. Short-term power load forecasting based on IVL-BP neural network technology. Syst. Eng. Procedia 2012, 4, 168-174. [CrossRef]

48. Granville, V.; Krivanek, M.; Rasson, J.-P. Simulated annealing: A proof of convergence. IEEE Trans. Pattern Anal. Mach. Intell. 1994, 16, 652-656. [CrossRef]

49. Aho, K.; Derryberry, D.; Peterson, T. Model selection for ecologists: The worldviews of AIC and BIC. Ecology 2014, 95, 631-636. [CrossRef]

50. Zhang, J.-C.; Pu, R.-L.; Wang, J.-H.; Huang, W.-J.; Yuan, L.; Luo, J.-H. Detecting powdery mildew of winter wheat using leaf level hyperspectral measurements. Comput. Electron. Agric. 2012, 85, 13-23. [CrossRef]

51. Huang, L.; Wu, Z.; Huang, W.; Ma, H.; Zhao, J. Identification of Fusarium Head Blight in Winter Wheat Ears Based on Fisher's Linear Discriminant Analysis and a Support Vector Machine. Appl. Sci. 2019, 9, 3894. [CrossRef]

52. $\mathrm{Xu}, \mathrm{W}$.; Wang, Q.; Chen, R. Spatio-temporal prediction of crop disease severity for agricultural emergency management based on recurrent neural networks. GeoInformatica 2017, 22, 363-381. [CrossRef]

53. Adam, E.; Deng, H.; Odindi, J.; Abdel-Rahman, E.M.; Mutanga, O. Detecting the Early Stage of Phaeosphaeria Leaf Spot Infestations in Maize Crop Using In Situ Hyperspectral Data and Guided Regularized Random Forest Algorithm. J. Spectrosc. 2017, 2017, 1-8. [CrossRef]

54. Aparecido, L.E.D.O.; Rolim, G.D.S.; Moraes, J.R.D.S.C.D.; Costa, C.T.S.; De Souza, P.S. Machine learning algorithms for forecasting the incidence of Coffea arabica pests and diseases. Int. J. Biometeorol. 2020, 64, 671-688. [CrossRef]

55. Zhang, J.; Yuan, L.; Pu, R.; Loraamm, R.W.; Yang, G.; Wang, J. Comparison between wavelet spectral features and conventional spectral features in detecting yellow rust for winter wheat. Comput. Electron. Agric. 2014, 100, 79-87. [CrossRef]

56. Liu, L.; Dong, Y.; Huang, W.; Du, X.; Luo, J.; Huang, W.; Ma, H. Enhanced Regional Monitoring of Wheat Powdery Mildew Based on an Instance-Based Transfer Learning Method. Remote Sens. 2019, 11, 298. [CrossRef]

57. Vanegas, F.; Bratanov, D.; Powell, K.S.; Weiss, J.; Gonzalez, F. A Novel Methodology for Improving Plant Pest Surveillance in Vineyards and Crops Using UAV-Based Hyperspectral and Spatial Data. Sensors 2018, 18, 260. [CrossRef]

58. Zhang, X.; Han, L.; Dong, Y.; Huang, W.; Huang, W.; Han, L.; González-Moreno, P.; Ma, H.; Ye, H.; Sobeih, T. A Deep Learning-Based Approach for Automated Yellow Rust Disease Detection from High-Resolution Hyperspectral UAV Images. Remote Sens. 2019, 11, 1554. [CrossRef]

59. Abdulridha, J.; Batuman, O.; Ampatzidis, Y. UAV-based remote sensing technique to detect citrus canker disease utilizing hyperspectral imaging and machine learning. Remote Sens. 2019, 11, 1373. [CrossRef]

60. Laguette, S.; MacRae, I.V. Potentials and limits of remote sensing data for detection of Fusarium head blight on hard red spring wheat in Minnesota. In Proceedings of the 7th International Conference on Precision Agriculture and Other Precision Resources Management, Minneapolis, MN, USA, 25-28 July 2004.

61. Barbedo, J.G.A.; Tibola, C.S.; Fernandes, J.M. Detecting Fusarium head blight in wheat kernels using hyperspectral imaging. Biosyst. Eng. 2015, 131, 65-76. [CrossRef] 
62. Jaillais, B.; Roumet, P.; Pinson-Gadais, L.; Bertrand, D. Detection of Fusarium head blight contamination in wheat kernels by multivariate imaging. Food Control 2015, 54, 250-258. [CrossRef]

63. Bauriegel, E.; Giebel, A.; Geyer, M.; Schmidt, U.; Herppich, W.B. Early detection of Fusarium infection in wheat using hyper-spectral imaging. Comput. Electron. Agric. 2011, 75, 304-312. [CrossRef]

64. Bauriegel, E.; Giebel, A.; Herppich, W.B. Hyperspectral and Chlorophyll Fluorescence Imaging to Analyse the Impact of Fusarium culmorum on the Photosynthetic Integrity of Infected Wheat Ears. Sensors 2011, 11, 3765-3779. [CrossRef]

65. Kang, Z.; Qu, Z. Application of BP neural network optimized by genetic simulated annealing algorithm to prediction of air quality index in Lanzhou. In Proceedings of the 2017 2nd IEEE International Conference on Computational Intelligence and Applications (ICCIA), Beijing, China, 8-11 September 2017; Institute of Electrical and Electronics Engineers (IEEE): Piscataway, NJ, USA, 2017; pp. 155-160.

66. Li, C.; Xu, S.; Wen, X. Traffic flow forecasting algorithm using simulated annealing genetic BP network. In Proceedings of the 2010 International Conference on Measuring Technology and Mechatronics Automation, Changsha, China, 13-14 March 2010; Institute of Electrical and Electronics Engineers (IEEE): Piscataway, NJ, USA, 2010; Volume 3, pp. 1043-1046.

67. Wang, Y.; Jiang, Y.; Lei, X.; Hao, W. Rainfall-runoff simulation using simulated annealing wavelet BP neural networks. In Proceedings of the 2010 International Conference on Intelligent Computation Technology and Automation, Changsha, China, 11-12 May 2010; Institute of Electrical and Electronics Engineers (IEEE): Piscataway, NJ, USA, 2010; Volume 2, pp. 963-967.

68. Liu, B.; Wang, R.; Zhao, G.; Guo, X.; Wang, Y.; Li, J.; Wang, S. Prediction of rock mass parameters in the TBM tunnel based on BP neural network integrated simulated annealing algorithm. Tunn. Undergr. Space Technol. 2020, 95, 103103. [CrossRef]

69. Ball, J.E.; Anderson, D.T.; Chan, C.S. Comprehensive survey of deep learning in remote sensing: Theories, tools, and challenges for the community. J. Appl. Remote Sens. 2017, 11, 042609. [CrossRef]

70. Zhang, D.; Wang, D.; Gu, C.; Jin, N.; Zhao, H.; Chen, G.; Liang, H.; Liang, D. Using Neural Network to Identify the Severity of Wheat Fusarium Head Blight in the Field Environment. Remote Sens. 2019, 11, 2375. [CrossRef]

71. Cambaza, E.; Koseki, S.; Kawamura, S. Why RGB Imaging Should be Used to Analyze Fusarium Graminearum Growth and Estimate Deoxynivalenol Contamination. Methods Protoc. 2019, 2, 25. [CrossRef]

72. Qiu, R.; Yang, C.; Moghimi, A.; Jian, Y.; Steffenson, B.; Hirsch, C.D. Detection of Fusarium Head Blight in Wheat Using a Deep Neural Network and Color Imaging. Remote Sens. 2019, 11, 2658. [CrossRef]

73. Dammer, K.-H.; Möller, B.; Rodemann, B.; Heppner, D. Detection of head blight (Fusarium ssp.) in winter wheat by color and multispectral image analyses. Crop. Prot. 2011, 30, 420-428. [CrossRef]

Publisher's Note: MDPI stays neutral with regard to jurisdictional claims in published maps and institutional affiliations.

(C) 2020 by the authors. Licensee MDPI, Basel, Switzerland. This article is an open access article distributed under the terms and conditions of the Creative Commons Attribution (CC BY) license (http://creativecommons.org/licenses/by/4.0/). 